\title{
Unlicensed medical practitioners in tribal dominated rural areas of central India: bottleneck in malaria elimination
}

\author{
Mrigendra Pal Singh ${ }^{1 *} \mathbb{D}$, Sunil Kumar Chand ${ }^{1}$, Kalyan Brata Saha ${ }^{2}$, Neetiraj Singh ${ }^{3}$, Ramesh C. Dhiman ${ }^{4}$ \\ and Lora L. Sabin ${ }^{5}$
}

\begin{abstract}
Background: In India, Accredited Social Health Activists (ASHAs) deliver services for diagnosis and treatment of malaria, although unlicensed medical practitioners (UMPs) (informal health providers) are most preferred in communities. A cross sectional survey was conducted to: (i) assess knowledge and treatment-seeking practices in the community, and (ii) explore the diagnosis and treatment practices related to malaria of UMPs working in rural and tribaldominated high malaria endemic areas of central India, and whether they adhere to the national guidelines.

Methods: A multi-stage sampling method and survey technique was adopted. Heads of the households and UMPs were interviewed using a structured interview schedule to assess knowledge and malaria treatment practices.

Results: Knowledge regarding malaria symptoms was generally accurate, but misconceptions emerged related to malaria transmission and mosquito breeding places. Modern preventive measures were poorly accessed by the households. UMPs were the most preferred health providers (49\%) and the first choice in households for seeking treatment. UMPs typically lacked knowledge of the names of malaria parasite species and species-specific diagnosis and treatment. Further, irrational use of anti-malarial drugs was common.
\end{abstract}

Conclusions: UMPs were the most preferred type of health care providers in rural communities where health infrastructure is poor. The study suggests enhancing training of UMPs on national guidelines for malaria diagnosis and treatment to strengthen their ability to contribute to achievement of India's malaria elimination goals.

Keywords: Irrational use of antimalarial drugs, Monotherapy of artemisinin, Plasmodium falciparum, Tribal malaria, Unlicensed medical practitioner

\section{Background}

The World Health Organization (WHO) recommends use of artemisinin-based combination therapy (ACT) for treatment of uncomplicated Plasmodium falciparum malaria [1]. In India, ACT has been the first-line treatment of confirmed P. falciparum malaria nationwide

\footnotetext{
*Correspondence: mrigendrapal@gmail.com

${ }^{1}$ ICMR-National Institute of Malaria Research Field Unit Jabalpur, NIRTH Campus, Nagpur Road, Post Garha, Jabalpur 482003, Madhya Pradesh, India

Full list of author information is available at the end of the article
}

since 2010, after artemisinin monotherapy was banned in 2009 [2]. Chloroquine is the first-line drug for treatment of confirmed Plasmodium vivax malaria [3]. Primaquine is also recommended in a single dose for $P$. falciparum and a 14-day dose for P. vivax [3]. Malaria is the most common cause of fever in tribal-dominated areas of central India [4]; P. falciparum and P. vivax are the most common species in this area, with P. falciparum the most dominant species [4]. Anopheles culicifacies is the primary vector of malaria in central India [5].

People living in tribal-dominated hilly forested areas are highly vulnerable to malarial infections due to

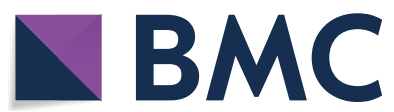

(c) The Author(s) 2020. This article is licensed under a Creative Commons Attribution 4.0 International License, which permits use, sharing, adaptation, distribution and reproduction in any medium or format, as long as you give appropriate credit to the original author(s) and the source, provide a link to the Creative Commons licence, and indicate if changes were made. The images or other third party material in this article are included in the article's Creative Commons licence, unless indicated otherwise in a credit line to the material. If material is not included in the article's Creative Commons licence and your intended use is not permitted by statutory regulation or exceeds the permitted use, you will need to obtain permission directly from the copyright holder. To view a copy of this licence, visit http://creativeco mmons.org/licenses/by/4.0/. The Creative Commons Public Domain Dedication waiver (http://creativecommons.org/publicdomain/ zero/1.0/) applies to the data made available in this article, unless otherwise stated in a credit line to the data. 
geo-climatic factors and poor access to health facilities. Further, in many communities, a poor understanding of the aetiology of malaria and various cultural practices add to this vulnerability [6, 7]. Low literacy levels and poor economic conditions also pose constraints for prompt diagnosis and treatment-seeking in the community [8]. Under the umbrella of the National Rural Health Mission, a cadre of female community volunteers known as Accredited Social Health Activists (ASHAs) was created to deliver rural health care services, mainly related to maternal and child health and vector borne diseases [2]. However, in many rural communities, particularly in tribal areas, unlicensed medical practitioners (UMPs) (informal health providers) are most preferred providers, including for treatment of malaria [7].

According to an estimate in India, among private health providers $57 \%$ had no recognized medical qualification, but they practice some form of allopathic medicine $[9,10]$. They mainly treat common illnesses like diarrhoea, fever, malaria, vomiting, rashes, joint pains, respiratory distress, abdominal pain, flu, and typhoid. Poor health infrastructure and absenteeism among formal health workers make rural UMPs easier to reach [11], which has resulted in a treatment system in rural tribal areas whereby UMPs play a significant role as health service providers. Although, they do not have the legal right or status to provide health care services, their role is critical because they work in remote rural areas where medical facilities are scarce [11].

A cross sectional survey was conducted with two main objectives: (i) to assess the knowledge and treatmentseeking practices of the community, and (ii) to explore the diagnosis and treatment practices related to malaria of UMPs working in rural and tribal-dominated high malaria endemic areas of central India, and its adherence to the national guidelines.

\section{Methods}

\section{Sample size and sampling methods}

In India, about $50 \%$ of the population receive health care services for febrile illness from informal providers $[7,11,12]$. Based on this proportion, a sample size was determined for household-level interviews to assess the utilization of health care services. Considering 5\% precision and a design effect of 2 , with an additional $30 \%$ to account for non-responses, a sample of 1000 households was determined for the household survey.

A multi-stage sampling method was adopted (Fig. 1). First, all of the 51 districts of Madhya Pradesh were grouped into four clusters based on proportion of tribal population, as follows: $0-10 \%$ (16 districts), $11-30 \%$ (19 districts), $31-40 \%$ (6 districts) and over 40\% (10 districts). Cluster one districts were excluded due to their low proportions of tribal residents. Districts in each cluster which had less than one annual parasite incidence (API), defined as the number of malaria-positive cases per one thousand populations during one calendar year, were also excluded. Of the remaining districts, two from cluster two (Balaghat and Sheopur), one from cluster three (Chhindwara), and two from cluster four (Betul and Shahdol) were randomly selected for the household survey (Fig. 2). These five districts accounted for $10 \%$ of the total state population and $16 \%$ of the state's tribal population [13]; they also contributed about $20 \%$ of malaria cases [14]. Second, one administrative block in each district was selected purposively based on the highest proportion of tribal population and malaria cases. Ten villages were then selected randomly from each block employing probability proportional to size (PPS) sampling method. Finally, 20 households in each village were selected from the listing of households by systematic random sampling. In any selected village where 20 households were not available, the remaining households were covered from a nearby village. This was the case for three villages; therefore, three more villages were added. In addition, a few extra households were sampled during the course of data collection due to precautions taken by the investigators to avoid under sampling. Therefore, at the end of the study, a total of 1010 households were included in the survey, all of which were included in the analysis (also shown in Fig. 1).

All surveys were conducted in Hindi, the most common language locally, by trained interviewers with graduate-level educational qualification. Structured interview schedule was designed to interview the head of the each household to collect data on educational status and occupation of the family members, knowledge related to malaria aetiology, mode of transmission, mosquito breeding places, prevention and treatmentseeking practices of the heads of the households using recall method for 2 weeks reference period of febrile illness. Availability of health infrastructure nearby the studied villages and distance from village was observed and recorded by the interviewers from various sources. As the UMPs were not legally-authorized health care providers, they were difficult to identify and approach for the study. Therefore, household respondents were asked to help the investigators identify UMPs who were providing health care services in the community. Once a group of UMPs were identified, they were further used through snowballing technique to identify and recruit additional UMPs. Surveys with UMPs used a semi-structured, pre-tested interview schedule consisting variables to inquire their educational status, knowledge related to malaria aetiology, mode of transmission, common species of human plasmodia 


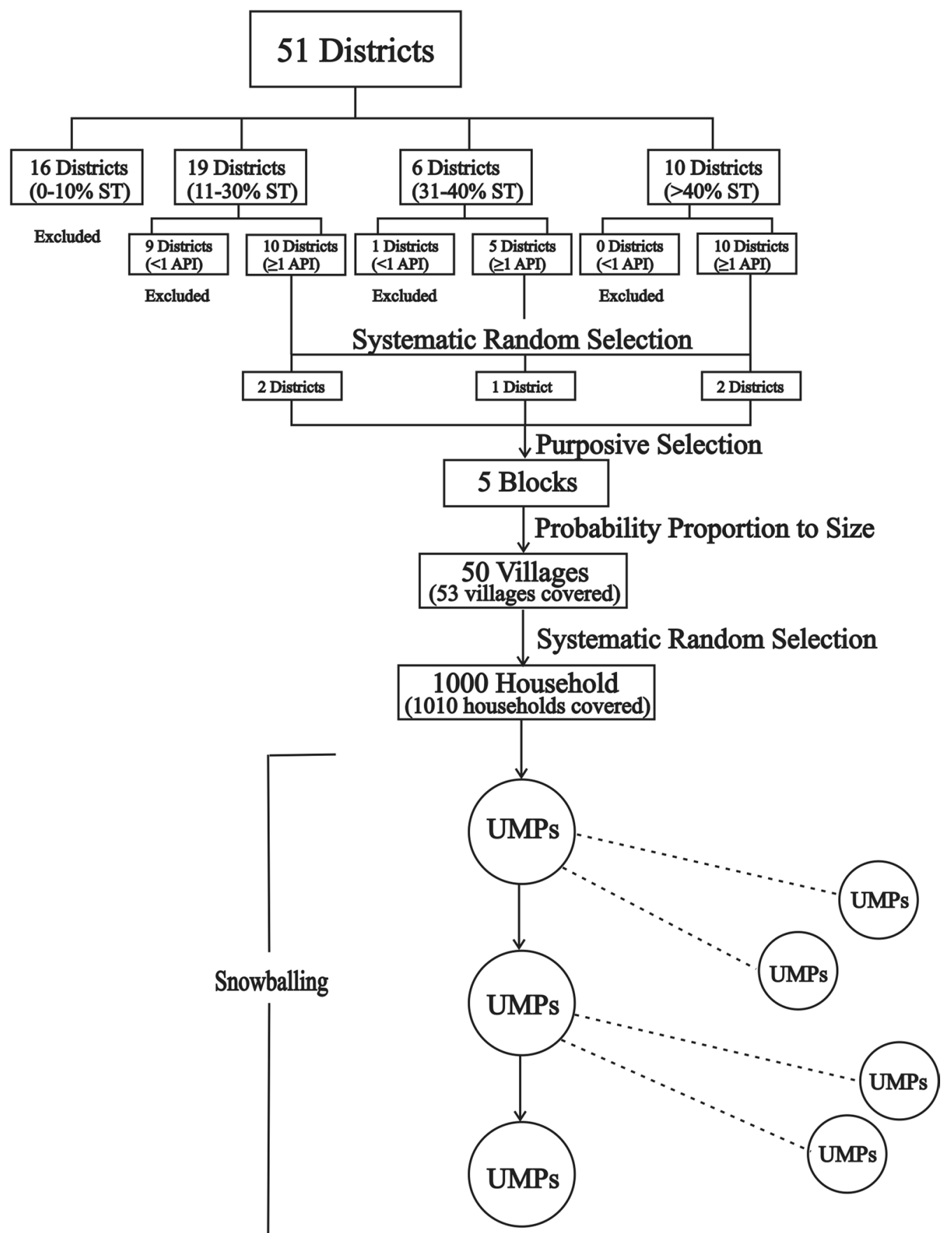

Fig. 1 Sampling method for selection of study participants. ST: Scheduled tribe; API: Annual parasite incidence; UMPs: Unlicensed medical practitioners

and their methods of diagnosis and treatment practices related to malaria. Average number of patients treated and the cost of treatment per patient was estimated based on responses reported by UMPs during interview using recall method for 1 week preceding the survey as reference period.

\section{Data entry and analysis}

Survey interview schedules were checked for completeness; illogical or inconsistent responses were edited before leaving the field site. Random spot checks and back-checks during interviews were conducted to ensure data quality control. Data were double key-entered in 


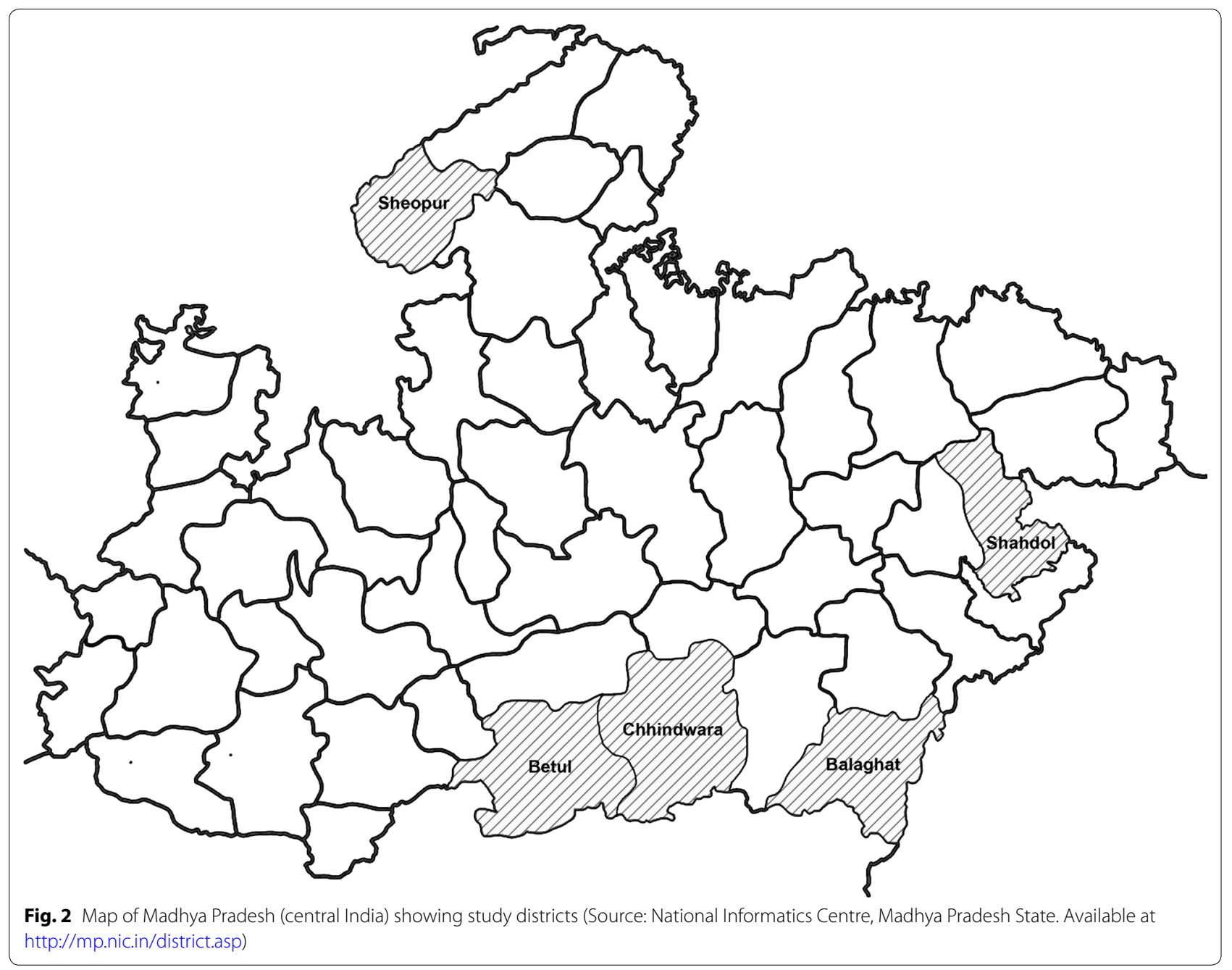

CSPro 7.1.3 (US Census Bureau) with built-in data entry application and edit checks for quality control. Data were then exported to $\mathrm{R}$ v3.5.0 for Windows ( $\mathrm{R}$ foundation for statistical computing) for statistical analysis. Numerically coded categorical variables were cross-tabulated in frequency and percentage distribution and continuous variables were summarized in mean and standard deviation (SD).

\section{Results}

\section{Demographic and Socio-economic characteristics} of the households

A total of 1010 households were surveyed, of which $85 \%$ belonged to different tribal groups. 'Baiga' tribe in Balaghat and Shahdol, 'Bharia' tribe in Chhindwara, 'Saharia' in Sheopur, and 'Gond' tribe, another dominant tribal group in all four districts except Sheopur, were represented in the study. The average family size was 5.6 per household, which was slightly higher than the average state-wide family size (4.7 persons per household) [13]. The sex ratio of the household members was 982 females per 1000 males, which was also higher than sex ratio of the state (931), as reported in census 2011 [13]. The literacy rate of household members above 6 years of age was $69 \%$, below the state-reported rate of $71 \%$, reported in census 2011 [13]. Agriculture (54\%) and casual labour (43\%) were the main occupations of residents. Only a small proportion of the population was engaged in salaried jobs $(3 \%)$ or small businesses $(1 \%)$ (Table 1$)$.

\section{Common ailments, knowledge, prevention} and treatment-seeking practices of the households for malaria

Fever, cold, cough, and diarrhoea were the most common health problems reported by heads of households in the study area. Misconceptions related to the mode of transmission of malaria were very common. Less than half of the heads of households knew that mosquito bites were 
Table 1 Education and occupation of study population and UMPs

\begin{tabular}{lll}
\hline Variables & $\begin{array}{l}\text { Households } \\
(\mathbf{N}=1010)\end{array}$ & UMPs (N= 140) \\
& $\mathbf{n}(\%)$ & $\mathbf{n}(\%)$ \\
\hline $\begin{array}{l}\text { Educational status (above 6 years of } \\
\text { age) }\end{array}$ & $\mathrm{N}=4552$ & \\
Illiterate & $1412(31.0)$ & 0 \\
Primary & $1277(28.0)$ & 0 \\
Middle & $915(20.1)$ & 0 \\
High school & $601(13.2)$ & $21(15.0)$ \\
Higher secondary & $235(5.2)$ & $53(37.9)$ \\
Graduate & $112(2.5)$ & $34(24.3)$ \\
Post graduate & 0 & $9(6.4)$ \\
Diploma/certificate & 0 & $9(6.4)$ \\
Other unspecific & 0 & $14(10.0)$ \\
Major occupation (above 14 years of & $\mathrm{N}=3709$ & \\
age) & & \\
Labourer & $1577(42.5)$ & na \\
Agriculture & $1989(53.6)$ & na \\
Salaried job & $105(2.8)$ & na \\
Business & $38(1.0)$ & na \\
\hline
\end{tabular}

na: not applicable

responsible for the spread of malaria in the community. Furthermore, regarding breeding places of mosquitoes, about two-thirds of heads of households responded that mosquitoes breed in mud, swamps, cow dung, forests, bushes, and shrubs. A higher proportion were aware that fever with chills and rigor, headaches, body aches, and vomiting are the main symptoms related to malaria. About $75 \%$ of the heads of households considered malaria a serious disease and believed it could be fatal if not treated promptly (72\%) (Table 2 ).

Most heads of households (>90\%) believed in the efficacy of indoor residual spraying of insecticide for malaria control. However, it was a normal practice in the area to paint the dwellings twice a year, mainly after the rainy season and in summer, which likely reduced the residual effect of the insecticide sprayed. Ownership of bed nets was highest in households residing in Balaghat (97\%), followed by Betul (69\%), Shahdol (46\%), Chhindwara (45\%) and Sheopur (3\%). This difference may be due to the distribution of bed nets under the government's malaria control programme, which was further confirmed by household heads and programme officials. Unaffordability due to the poor economic condition of most households was the major reason for not owning a bed net. For protection from mosquito bites, most households produced smoke by burning leaves and cow dung (65\%), used cloths to cover most of the body (16\%), and rubbed mustard oil on the body (23\%). A smaller proportion
(36\%) of households practiced modern preventive measures like regular use of bed nets, mosquito repellents, coils, and cakes (Table 3 ).

UMPs were the most preferred health providers (49\%) in the community, and were residents' first choice for seeking treatment of ailments. About $15 \%$ of the households sought treatment from faith/herbal healers, 15\% went to community health workers like ASHAs, Auxiliary Nurse Midwives (ANMs), 15\% visited government hospitals like primary health centres (PHCs) or community health centres $(\mathrm{CHCs})$, and $6 \%$ went to private hospitals as their first choice for treatment during an illness. However, $60-70 \%$ of the household heads believed that diagnosis and treatment of febrile illness was freely available within the village and was provided by the ASHAs, which contrasts sharply with their practices (Table 3 ).

\section{Health infrastructure availability}

Integrated child development scheme (ICDS) services by the Government of India through ICDS centres and its workers within the villages were available to more than $90 \%$ of the villages. ASHAs were providing primary health services in over $80 \%$ of the villages. However, peripheral community health providers like ANMs, health sub-centres, and village level health committees were less available in the villages (11-18\%). The average distance of any government health facility such as PHCs and $\mathrm{CHCs}$ from the villages was 13.2 (SD: 1.9) and 28.6 (SD: 10.1) km, respectively. The mean distance of public bus stops from villages was recorded to be 6.4 (SD: 3.6) $\mathrm{km}$ (Table 4). Public transportation was very poor in the study areas.

\section{Knowledge, perception, and practices of UMPs}

A total of 168 UMPs were identified of which 28 were not willing to participate in the study, rest 140 UMPs were interviewed. All the UMPs were male with an average age of 33.3 (SD: 8.1 ) years. About $50 \%$ of the participants had completed up to secondary level of school education, $24 \%$ were graduates (with non-medical degree), $6 \%$ were post-graduates with non-medical degrees, and $6 \%$ had acquired a short term certificate or diploma in Medical Laboratory Technology, Certificate of Training of "Jan Swasthya Rakshak" (Village Health Guide). The remaining $10 \%$ had other training certificates from unrecognized agencies or organizations (Table 1 ).

The UMPs had 2-15 years of experience (average of 8.3; SD: 3.1 years) providing health care services and were treating patients mostly for common illness such as malaria, typhoid, cold and cough, diarrhoea, and skin diseases. Most (79\%) of the UMPs knew about the aetiology (cause and clinical symptoms) of malaria. However, the remaining $21 \%$ of the UMPs had misconceptions about 
Table 2 Knowledge of malaria aetiology among community and UMPs

\begin{tabular}{|c|c|c|}
\hline Variables & $\begin{array}{l}\text { Households }(\mathrm{N}=1010) \\
\mathrm{n}(\%)\end{array}$ & $\begin{array}{l}\text { UMPs }(N=140) \\
n(\%)\end{array}$ \\
\hline \multicolumn{3}{|l|}{ Main symptoms of malaria } \\
\hline Fever with chills \& rigor & $932(92.3)$ & $130(92.9)$ \\
\hline Headache, bodyache & $895(88.6)$ & $124(88.6)$ \\
\hline Vomiting, nausea & $830(82.2)$ & $131(93.6)$ \\
\hline Unconsciousness & 0 & $5(3.6)$ \\
\hline Diarrhoea & $268(26.5)$ & 0 \\
\hline Cold \& cough, throat sore, runny nose & $535(53.0)$ & 0 \\
\hline Jaundice & $86(8.5)$ & $4(2.9)$ \\
\hline \multicolumn{3}{|l|}{ Mode of transmission of malaria } \\
\hline Mosquito bite causes malaria & $409(40.5)$ & $110(78.6)$ \\
\hline Other fly, bedbug, contaminated food/water etc. & $601(59.5)$ & $30(21.4)$ \\
\hline \multicolumn{3}{|l|}{ Mosquito breeding place } \\
\hline Mud, swamp, cow dung & $455(45.0)$ & $78(55.7)$ \\
\hline Water & $390(38.6)$ & $62(44.3)$ \\
\hline Forest, shrubs & $165(16.3)$ & 0 \\
\hline \multicolumn{3}{|l|}{ Preventive measures } \\
\hline Sleeping under bednet & $571(56.5)$ & $47(33.7)$ \\
\hline Elimination of mosquito breeding places & $86(19.6)$ & $93(66.3)$ \\
\hline Smoke burning leaves and cow dung & $661(65.4)$ & $27(19.3)$ \\
\hline Mosquito repellent like coil cake & $13(1.3)$ & $109(77.9)$ \\
\hline Indoor residual spray with insecticide & $289(28.6)$ & $11(7.9)$ \\
\hline \multicolumn{3}{|l|}{ Common ailments in the area } \\
\hline Fever & $875(86.6)$ & $136(97.1)$ \\
\hline Cold \& cough & $635(62.9)$ & $35(25.0)$ \\
\hline Diarrhoea & $578(57.2)$ & $57(40.7)$ \\
\hline Skin disease & $166(16.4)$ & $11(7.9)$ \\
\hline Tuberculosis & $104(10.3)$ & $8(5.7)$ \\
\hline Eye disease & $29(2.9)$ & 0 \\
\hline Jaundice & $226(22.4)$ & $2(1.4)$ \\
\hline Other (typhoid, viral fever) & $154(15.2)$ & $15(10.7)$ \\
\hline Malaria a serious health problem & $755(74.8)$ & $128(91.4)$ \\
\hline Malaria is fatal & $724(71.7)$ & $131(93.6)$ \\
\hline \multicolumn{3}{|l|}{ Species of human malaria parasite } \\
\hline P. falciparum & - & $115(82.1)$ \\
\hline P. vivax & - & $15(10.7)$ \\
\hline P. malariae & - & 0 \\
\hline P.ovale & - & 0 \\
\hline P. knowlesi & - & 0 \\
\hline P. falciparum and P. vivax & - & $10(7.2)$ \\
\hline Wrong answer i.e. filaria, dengue etc. & - & $9(6.4)$ \\
\hline \multicolumn{3}{|l|}{ Most common species in the area } \\
\hline P. falciparum only & - & $124(88.6)$ \\
\hline P. vivax only & - & $3(2.1)$ \\
\hline P. falciparum and $P$. vivax both & - & $4(2.9)$ \\
\hline Wrong answer i.e. filaria, dengue etc. & - & $9(6.4)$ \\
\hline \multicolumn{3}{|l|}{ Methods for malaria diagnosis } \\
\hline Blood test by RDT only & - & $2(1.4)$ \\
\hline Blood test by microscopy only & - & $2(1.4)$ \\
\hline Blood test by RDT and microscopy both & - & $136(97.1)$ \\
\hline
\end{tabular}

-: not collected from household at community level 
Table 3 Malaria prevention and treatment seeking practices among community

\begin{tabular}{|c|c|}
\hline Variables & $\mathrm{n} / \mathrm{d}(\%)$ \\
\hline \multicolumn{2}{|l|}{ Prevention practices from mosquito bite } \\
\hline House was sprayed with insecticide (IRS) & 289/1010 (28.6) \\
\hline IRS including kitchen & $227 / 289(78.5)$ \\
\hline Household like IRS & $983 / 1010(97.3)$ \\
\hline Household feels that IRS is effective & $954 / 1010(94.5)$ \\
\hline House was whitewash (Mean \pm SD) per year & $1.9 \pm 0.7$ \\
\hline Household heard about insecticide treated bednets & $435 / 1010(43.1)$ \\
\hline Household owned bednet & $571 / 1010(56.5)$ \\
\hline No. of bednet (Mean \pm SD) per household & $1.6 \pm 0.9$ \\
\hline \multicolumn{2}{|l|}{ Reasons for not owing/using bednet $(\mathrm{N}=439)$} \\
\hline Economic & $321 / 439(73.1)$ \\
\hline Mosquito not bite & 86/439 (19.6) \\
\hline Feel uncomfortable & $32 / 439(7.3)$ \\
\hline Owned insecticide treated bednet $(N=571)$ & $438 / 571(76.7)$ \\
\hline $\begin{array}{l}\text { Bednet provided by the government agency } \\
(N=571)\end{array}$ & $438 / 571(76.7)$ \\
\hline $\begin{array}{l}\text { Using any preventive measures to protect from mos- } \\
\text { quito bite }\end{array}$ & $873 / 1010(86.4)$ \\
\hline Sleeping under bednet regularly & $360 / 1010(35.6)$ \\
\hline Using mosquito repellent coil, cake, cream & $13 / 1010(1.3)$ \\
\hline Smoke formation by burning leaves, cow dung & $661 / 1010(65.4)$ \\
\hline Roping body oil & $236 / 1010(23.4)$ \\
\hline Cover body & $165 / 1010(16.3)$ \\
\hline Other & 0 \\
\hline $\begin{array}{l}\text { Any one suffered from suspected malaria in } 2 \text { weeks } \\
\text { preceding the survey }\end{array}$ & $390 / 1010(38.6)$ \\
\hline \multicolumn{2}{|l|}{ Initial source of treatment sought $(\mathrm{N}=390)$} \\
\hline Faith/traditional healer & $57 / 390(14.6)$ \\
\hline Unqualified health providers & 193/390 (49.5) \\
\hline ASHA/ANM/health worker & $57 / 390(14.6)$ \\
\hline PHC/CHC govt hospital & $58 / 390(14.9)$ \\
\hline Private hospital & $25 / 390(6.4)$ \\
\hline $\begin{array}{l}\text { Malaria diagnosis/treatment is available within the } \\
\text { village }\end{array}$ & $599 / 1010(59.3)$ \\
\hline Treatment was freely provided & $452 / 599(75.5)$ \\
\hline Availed free malaria treatment within the village & $422 / 599(70.4)$ \\
\hline Satisfied with provided free malaria treatment & $402 / 599(67.1)$ \\
\hline
\end{tabular}

$\mathrm{n} / \mathrm{d}$ : Numerator/denominator

a Refers to reported malaria

the mode of transmission of the disease and reported that house flies, bedbugs, and consuming contaminated water or food also caused malaria infection. More than $50 \%$ of the UMPs were not aware of the proper breeding places of mosquitoes and lacked knowledge regarding modern preventive measures for malaria (Table 2). Knowledge about human plasmodia was also inadequate; $82 \%$ of the UMPs knew only $P$. falciparum species, $11 \%$ knew only $P$. vivax, 7\% knew both $P$. falciparum and $P$. vivax. Around
Table 4 Health infrastructure availability in study villages

\begin{tabular}{ll}
\hline Variables & $\begin{array}{l}\mathbf{( N = 5 3 )} \\
\mathbf{n}(\%)\end{array}$ \\
\hline Health Infrastructure available in the villages & \\
Aagnawadi (ICDS) centre & $52(98.1)$ \\
Aaganwadi (ICDS) assistant & $48(90.6)$ \\
Aaganwadi (ICDS) worker & $48(90.6)$ \\
Aaganwadi (ICDS) is functioning regularly & $48(90.6)$ \\
ASHA worker is residing in the village & $45(84.9)$ \\
Health sub-centre available in the village & $10(18.9)$ \\
Nurse is residing in the village & $6(11.3)$ \\
Health committee is functioning in the village & $10(18.9)$ \\
Distance of Health facilities from the village & \\
PHCs (mean \pm SD) km & $13.2 \pm 1.9$ \\
CHCS (mean \pm SD) km & $28.6 \pm 10.1$ \\
Distance of bus stop (mean \pm SD) km & $6.4 \pm 3.6$ \\
Vehicle available in emergency in the villages & $35(66.0)$ \\
\hline
\end{tabular}

$6 \%$ reported filaria and dengue as names of species of Plasmodium (Table 2).

The average charge for the diagnosis and treatment of any disease was 4.27 USD per patient, which varied with type of the disease and patient condition. In 1 week before the survey, an average of 47.3 (SD: 34.9) patients were treated by the UMPs, of which 27.4 (SD: 24.7) patients had febrile illness and were suspected to be infected with malaria. Overall, $38 \%$ of UMPs admitted that they usually provide anti-malarial treatment to the suspected malaria cases without confirmed diagnosis; the remaining $62 \%$ mentioned that they provide treatment only after blood test using malaria rapid diagnostic test kit (RDT). Some of most recently used RDTs were physically verified by the interviewers during the survey. The malaria RDTs were procured from the local market. Injectable modes of treatment were most favoured $(67 \%)$ as per the choice exercised by the patients. Only $9 \%$ of the UMPs had heard about the national policy for diagnosis and treatment of malaria, though none had actually read the guidelines. Four percent of the UMPs mentioned that they had also treated serious and complicated malaria cases, which is not advised by the guidelines (such cases should refer to nearest health facilities).

Regarding the anti-malarial treatment practices for different parasite species, none of the UMPs adhered to the national drug policy; frequently they practiced monotherapy of artemisinin. It was also observed that $P$. falciparum cases were also treated with chloroquine, despite resistance in most part of the country. Small proportions of cases were also treated with quinine, which is not advisable in field conditions and requires 
strict medical supervision as per guidelines. Only $18 \%$ of $P$. falciparum and $5 \%$ P. vivax cases were provided primaquine, creating opportunities for further transmission of malaria in the community. The use of inappropriate regimes of anti-malarials with inadequate dosages for treatment of suspected and/or confirmed malaria cases was commonly observed and was noticed as a serious concern (Table 5).

\section{Discussion}

Malaria incidence was most pronounced in tribal dominated areas of the country [6]. These tribal dominated areas are hilly, forested, and inaccessible in much of the rainy season, which is the main transmission season for malaria [15]. Tribal communities preferred informal health providers, such as faith/traditional healers and unqualified or unlicensed medical practitioners. This preference is less by choice than by necessity due to low literacy levels, poor economic conditions, and inadequate health infrastructure which act to limit awareness of disease transmission and prevention, diagnosis, and treatment $[6,7,11]$. UMPs are the first source of treatment providers for more than half the population in rural tribal areas [7, 11, 12]. Although UMPs lack medical degrees, they have self-acquired knowledge and experience administering allopathic medicines.

Despite their knowledge and experience, the survey results found many examples of inappropriate treatment practices. UMPs frequently treated $P$. falciparum patients with monotherapy of artemisinin, often with incomplete doses which can create drug pressure and lead to drug resistance [16]. It has also been reported in other studies that artemisinin mono-therapy has been prescribed by qualified allopathic and non-allopathic physicians for treatment of uncomplicated malaria in other areas [17]. UMPs also treated $P$. vivax patients with artemisinin, while many $P$. falciparum patients were treated with chloroquine, which is against the national treatment guidelines for malaria [18]. In addition, national guidelines state that quinine is only to be given to serious and complicated confirmed malaria patients under strict medical supervision [18].

This study confirmed that the poor health infrastructure in remote rural and inaccessible tribal dominant areas of the state compels community members to seek treatment from unlicensed private health providers, mainly because they cannot afford wage loss due to sickness [19]. Alternative health services are only available at locations too far away to be accessible [20]. Thus residents in these areas represent a vulnerable population unable to access malaria diagnosis and treatment services that adhere to national guidelines. While they do not receive the quality of services
Table 5 Treatment practices of UMPs particularly for malaria

\begin{tabular}{|c|c|}
\hline Variables & $\begin{array}{l}N=140 \\
n(\%)\end{array}$ \\
\hline Total length (mean \pm SD) of medical practice (year) & $8.3 \pm 3.1$ \\
\hline Attended any training programme & $125(89.3)$ \\
\hline Training provided by govt. agency & $40(28.6)$ \\
\hline Training period (months) (mean \pm SD) & $7.3 \pm 3.5$ \\
\hline Training on malaria diagnosis and treatment & $6(4.3)$ \\
\hline \multicolumn{2}{|l|}{ Major common diseases in area } \\
\hline Malaria & $136(97.1)$ \\
\hline Diarrhoea & $57(40.7)$ \\
\hline Skin disease & $11(7.9)$ \\
\hline Cough cold & $35(25.0)$ \\
\hline Typhoid & $6(4.3)$ \\
\hline Tuberculosis & $8(5.7)$ \\
\hline Viral Fever & $9(6.4)$ \\
\hline Jaundice & $2(1.4)$ \\
\hline \multicolumn{2}{|l|}{ Providing services on following health issues } \\
\hline Maternal health care & $72(51.4)$ \\
\hline Child health care & $106(75.7)$ \\
\hline Family planning & $124(88.6)$ \\
\hline Vaccination & $111(79.3)$ \\
\hline $\begin{array}{l}\text { Common diseases (diarrhoea, skin diseases, typhoid, } \\
\text { piles, asthma) }\end{array}$ & $140(100.0)$ \\
\hline Malaria & $138(98.6)$ \\
\hline Tuberculosis & $5(3.6)$ \\
\hline No. of patients treated in last week (mean \pm SD) & $47.3 \pm 34.9$ \\
\hline No. of fever cases treated in last week (mean \pm SD) & $27.4 \pm 24.7$ \\
\hline No. of malaria patient treated in last week (mean \pm SD) & $17.6 \pm 5.8$ \\
\hline $\begin{array}{l}\text { Usually treat suspected malaria cases based on clinical } \\
\text { symptoms }\end{array}$ & $53(37.9)$ \\
\hline $\begin{array}{l}\text { Treat suspected malaria cases only after blood test using } \\
\text { RDTs }\end{array}$ & $87(62.1)$ \\
\hline Having malaria RDT in stock (physically verified) & $127(90.7)$ \\
\hline \multicolumn{2}{|l|}{ Source of RDT procured } \\
\hline Market & $137(97.9)$ \\
\hline Government Hospital/ASHAs & $2(1.4)$ \\
\hline \multicolumn{2}{|l|}{ Source of antimalarial procured } \\
\hline Market & $138(98.6)$ \\
\hline Government hospital/ASHAs & $2(1.4)$ \\
\hline \multicolumn{2}{|l|}{ Mode of treatment preferred } \\
\hline Injectable & $94(67.1)$ \\
\hline Oral (tablets/syrup) & $15(10.7)$ \\
\hline Both & $31(22.1)$ \\
\hline \multicolumn{2}{|l|}{ Cause of preference of injectable } \\
\hline Patient psychology (client's preference) & $103(73.6)$ \\
\hline Fast recovery (provider's preference) & $37(26.4)$ \\
\hline Treated complicated/serious malaria patient & $6(4.3)$ \\
\hline $\begin{array}{l}\text { Heard about national diagnosis and treatment guidelines } \\
\text { of malaria }\end{array}$ & $12(8.6)$ \\
\hline
\end{tabular}


Table 5 (continued)

\begin{tabular}{ll}
\hline Variables & $\mathbf{N}=\mathbf{1 4 0}$ \\
& $\mathbf{n}(\%)$ \\
\hline $\begin{array}{l}\text { Treatment practices of malaria patients } \\
\text { E-Mal (artesunate injection) }\end{array}$ \\
$\quad$ P. falciparum \\
$\quad$ P. vivax & $95(67.9)$ \\
Quinine tablets & $17(12.1)$ \\
P. falciparum & \\
P. vivax & $2(1.4)$ \\
Quinine injection & $3(2.1)$ \\
P. falciparum & \\
P. vivax & $2(1.4)$ \\
Chloroquine tablets & $2(1.4)$ \\
P. falciparum & \\
P. vivax & $18(12.9)$ \\
Chloroquine injection & $31(22.1)$ \\
P. falciparum & \\
P. vivax & $11(7.9)$ \\
Primaquine tablets & $33(23.6)$ \\
P. falciparum & \\
P. vivax & $25(17.9)$ \\
\hline
\end{tabular}

obtained by residents in other parts of India, their ability to access UMPs provides them with providers who are described as hospitable and able to provide hasslefree, relatively low-cost medicines and services. These findings conform with those of a study conducted by Das and Mohpal in Madhya Pradesh, which revealed that most private providers in rural areas lack formal medical training, but they had spent more time with the patients and thus win over their trust [11].

While few of the UMPs acknowledged that they treated serious and complicated malaria cases instead of referring them to the nearest health facility, it is important to recognize that such treatment represents an important contribution given the scarcity of government health infrastructure in remote rural areas. This lack of trained human resources is an important factor for poor health delivery in rural areas. The educational background and skills of UMPs related to diagnosis and treatment might be stronger than those of ASHAs, who are primary health care providers in rural communities. Therefore, it is recommended that UMPs be trained as per the national guidelines for diagnosis and treatment of common illnesses, including malaria, to enhance their ability to play a significant role to achieving India's malaria elimination goals.

In 2009, a 6 months' training programme was organized in the state of Andhra Pradesh to develop treatment skills of common ailments and awareness among UMPs [21]. Similarly, in the state of Chhattisgarh, a three-year medical diploma course was initiated in 2001 to train health practitioners for rural areas. However, these programmes were aborted, mainly due to resistance from the Medical Council of India (MCI), the professional body regulating medical education in India. The MCI raised the issue that approval to practice medicine by UMPs may promote the irrational use of allopathic drugs and bring a medical catastrophe. In July 2019, the Government of India introduced National Medical Commission Bill, 2019, in assembly which may grant a limited license to certain mid-level practitioners (community health providers) connected with the modern medical profession to practice allopathic medicine. These mid-level practitioners may prescribe specified medicines in primary and preventive healthcare. In other situations, these practitioners may only prescribe medicines under the supervision of a registered medical practitioner [22].

\section{Conclusions}

Developing a well-designed training protocol for UMPs, particularly on anti-malarial treatment, may be useful in areas of India, along with limiting their role to be similar to that of health volunteers such as ASHAs and other programme-driven village-level health care providers, rather than giving them the status of a doctor. In addition to training and equipping UMPs to provide basic health services, including anti-malarial services, close monitoring of their capabilities should be enforced to ensure their credibility. Such activities, designed to incorporate trained UMPs into the existing programme for achieving India's malaria elimination goals in hard-to-reach tribal areas, can only bring positive results.

\section{Limitations}

All efforts were made to capture valid responses from the UMPs who participated in the study. Responses were collected only from UMPs who volunteered for the survey, and this might have resulted into certain amount of biasness. However, such bias was not so extensive and thus this possibility is not overly concerning.

\section{Abbreviations}

ASHAs: Accredited Social Health Activists; UMPs: unlicensed medical practitioners; WHO: World Health Organization; ACT: artemisinin based combination therapy; API: annual parasite incidence; PPS: probability proportional to size; SD: standard deviation; ANMs: auxiliary nurse midwives; PHCs: primary health centres; CHCs: community health centres; ICDS: integrated child development scheme; RDT: rapid diagnostic test; MCI: Medical Council of India.

\section{Acknowledgements}

The authors thank to Dr. Neena Valecha, former Director, ICMR-National Institute of Malaria Research, New Delhi, for providing support. The manuscript was approved by the Publication Screening Committee of ICMR-National Institute of Malaria Research, New Delhi (Reference no. 48/2018). 


\section{Authors' contributions}

MPS: conceptualized the study, study design, data analysis, data interpretation and prepare the first draft. SKC, NS: monitoring of data collection, data interpretation, review and write the manuscript. KBS: data analysis and data interpretation, review and write the manuscript. RCD: data interpretation, review and write the manuscript. LLS: data interpretation finalized the manuscript on the basis of comments from other authors. All authors read and approved the final manuscript.

\section{Funding}

Study was carried out with financial support from Tribal Development and Research Institute, Ministry of Tribal Affairs, Government of Madhya Pradesh, Bhopal, India. The funder of the study had no role in study design, data collection, data analysis, data interpretation, or writing of the report.

\section{Availability of data and materials}

The raw data collected and used in the present analysis will be available from the corresponding author on reasonable request.

\section{Ethics approval and consent to participate}

The study was approved by the Institutional Ethics Committee of ICMRNational Institute of Malaria Research, New Delhi, India. Informed consent from the heads of the households and UMPs was obtained before conducting interviews.

\section{Consent for publication}

All participants provided informed consent to have information shared through publication, with identifying information removed.

\section{Competing interests}

The authors declare that they have no competing interests.

\begin{abstract}
Author details
${ }^{1}$ ICMR-National Institute of Malaria Research Field Unit Jabalpur, NIRTH Campus, Nagpur Road, Post Garha, Jabalpur 482003, Madhya Pradesh, India. ${ }^{2}$ ICMR-National Institute of Research in Tribal Health, NIRTH Campus, Nagpur Road, Post Garha, Jabalpur 482003, Madhya Pradesh, India. ${ }^{3}$ Tribal Development and Research Institute, Ministry of Tribal Affairs, Government of Madhya Pradesh, 35 Shyamla Hills, Bhopal, India. ${ }^{4}$ ICMR-National Institute of Malaria Research, Sector 8, Dwarka, New Delhi 110077, India. ${ }^{5}$ Department of Global Health, Boston University School of Public Health, 801 Massachusetts Ave, Boston, MA, USA.
\end{abstract}

Received: 16 August 2019 Accepted: 8 January 2020

Published online: 14 January 2020

\section{References}

1. WHO. Guidelines for the treatment of malaria. Geneva, World Health Organization, 2015. http://www.who.int/malaria/publications/atoz/ meeting_briefing 19april.pdf. Accessed 28 Sep 2018.

2. NVBDCP. Strategic plan for malaria control in India 2012-2017. A five-year strategic plan'Scaling up malaria control interventions with a focus on high burden areas' and 'Categorized strategic interventions for achieving pre-elimination status'. Directorate of National Vector Borne Disease Control Programme, Directorate General of Health Services Ministry of Health \& Family Welfare Government of India 22-Shamnath Marg, Delhi 110054. http://nvbdcp.gov.in/Doc/StrategicAction-Plan-Malaria-2012-17-Co.pdf. Accessed 20 Sep 2018.

3. Guidelines for diagnosis and treatment of malaria in India. https:// www.researchgate.net/publication/327155827_Guidelines_for_diagn osis_and_treatment_of_malaria_in_india. Accessed 02 Dec 2019.

4. Singh N, Mishra AK, Shukla MM, Chand SK. Forest malaria in Chhindwara, Madhya Pradesh, central India: a case study in a tribal community. Am J Trop Med Hyg. 2003;68:602-7.

5. Singh N, Dash AP, Thimasarn K. Fighting malaria in Madhya Pradesh (Central India): Are we losing the battle? Malar J. 2009;8:93.

6. Sharma RK, Thakor HG, Saha KB, Sonal GS, Dhariwal AC, Singh N. Malaria situation in India with special reference to tribal areas. Ind J Med Res. 2015;141:537-45.
7. Singh MP, Saha KB, Chand SK, Anvikar A. Factors associated with treatment seeking for malaria in Madhya Pradesh. India. Trop Med Int Health. 2017:22:1377-84.

8. Singh MP, Saha KB, Chand SK, Savargaonkar D. Socio-economic determinants of community knowledge and practices related to malaria in high and low transmission areas of central India. J Biosoc Sci. 2019. https://doi.org/10.1017/S0021932019000440

9. Anand S, Fan V. The health workforce in India. Human Resources for Health Observer Series No. 16. Geneva, World Health Organization, 2016. http://www.who.int/hrh/resources/16058health_workforce_ India.pdf. Accessed 26 Sep 2018.

10. PIB. FAQs on National Medical Commission (NMC) Bill 2019. Clause 32: limited license to practice at Mid-Level as Community Health Provider. Press Information Bureau. Government of India. Ministry of Health and Family Welfare. http://pib.gov.in/newsite/PrintRelease.aspx?relid $=192491$. Accessed 16 Aug 2019.

11. Das J, Mohpal A. Socioeconomic status and quality of care in rural India: new evidence from provider and household surveys. Health Aff. 2016;35:1764-73.

12. Chaturvedi HK, Mahanta J, Pandey A. Treatment-seeking for febrile illness in north-east India: an epidemiological study in the malaria endemic zone. Malar J. 2009;8:301.

13. Census. Population enumeration data (final population). Office of the Registrar General \& Census Commissioner, India. Ministry of Home Affairs, Government of India. http://www.censusindia.gov.in/2011c ensus/population_enumeration.html. Accessed 26 Sep 2018.

14. SVBDCP. District wise malaria situation in Madhya Pradesh. Office of the State Programme Officer, Directorate of Health Services, Ministry of Health and Family Welfare, Government of Madhya Pradesh, Bhopal, India. 2018.

15. Singh N, Chand SK, Bharti PK, Singh MP, Chand G, Mishra AK, Shukla MM, Mahulia MM, Sharma RK. Dynamics of forest malaria transmission in Balaghat district, Madhya Pradesh. India. PLoS One. 2013;8:e73730.

16. Res P. Social and cultural complexities of anti-malarial drug circulation: an ethnographic investigation in three rural remote communes of Cambodia. Malar J. 2017;16:428.

17. Mishra N, Anvikar AR, Shah NK, Kamal VK, Sharma SK, Srivastava HC, et al. Prescription practices and availability of artemisinin monotherapy in India: where do we stand? Malar J. 2011;10:360.

18. NVBDCP. Guidelines for diagnosis and treatment of malaria in India. ICMR-National Institute of Malaria Research, New Delhi. National Vector Borne Disease Control Programme, Directorate General of Health Services Ministry of Health \& Family Welfare Government of India. http:// www.mrcindia.org/Diagnosis\%20of\%20Malaria\%20pdf/Guidelines \%202014.pdf. Accessed 20 Sep 2018.

19. Singh MP, Saha KB, Chand SK, Sabin LL. The economic cost of malaria at the household level in high and low transmission areas of central India. Acta Trop. 2019;190:344-9.

20. Chandra S. Unqualified medical practitioners in India. The legal, medical and social dimensions of their practices - a report. Pursuant to the award of a fellowship to the principal investigator by the centre for public affairs and critical theory-C-PACT Shiv Nadar university. https ://cpact.snu.edu.in/sites/default/files/UMP-BOOK\%20\%281\%29.pdf. Accessed 27 Sep 2018

21. Pulla P. Andhra Pradesh: the state that dared to train 'quacks' in medicine. In 2009, one Indian state took a chance on quacks to help solve its healthcare crisis. What happened? Mosaic Health Care. https://mosaicscience.com/story/andhra-pradesh-state-dared-train -\%E2\%80\%98quacks-medicine/ Accessed 28 Sep 2018.

22. PRS. PRS Legislative Research. The National Medical Commission Bill, 2019. Ministry of Health and Family Welfare. Government of India. http:// prsindia.org/billtrack/national-medical-commission-bill-2019. Accessed 16 Aug 2019.

\section{Publisher's Note}

Springer Nature remains neutral with regard to jurisdictional claims in published maps and institutional affiliations. 